\section{Palliative Care Ethics: a Good Companion}

Fiona Randall and R S Downie, United States, Oxford University Press, 1996, 195 pages, $£ 16.95$ pb, $£ 30$ hb.

Written jointly by a consultant in palliative medicine and a professor of moral philosophy, this book represents a profound treatise on many aspects of palliative care. The authors, modestly, call it a companion to conventional textbooks, but it is more than that. It calls into question many conventionally accepted assumptions, thereby posing some powerful challenges. Issues are raised in relation to information-giving, confidentiality, treatment decisions, team-work, research and other crucially important topics. The authors tackle many delicate concerns with professional and human integrity. The concluding section on resource allocation at macro- and micro-levels gives this work economic as well as professional credence. Whoever reads this book will be challenged to think. There will be points of agreement as well as disagreement between authors and readers. Thus, there is an abundance of extremely helpful material to stimulate informed debates.

As so aptly summed up in Dr Derek Doyle's foreword: palliative care will be the richer for the wisdom shared by the authors.

All who are in any way involved in palliative care, be it as health professionals, managers, economists or politicians, have a duty to read and discuss this important contribution to the literature.

LISBETH HOCKEY

Visiting Professor in Nursing Research, 1/2 Silverknowes Road, Edinburgh EH4 5NX

\section{The Moral Challenge of Alzheimer Disease}

\author{
Stephen G Post, Baltimore and \\ London, The Johns Hopkins \\ University Press, 1995, 142 pages, \\ $£ 25$.
}

This book provides a positive outlook on the moral status of people suffering from dementia. It challenges the assumption that dementia is necessarily associated with a lower quality and value of life. It provides an alternative position to the "hypercognitive" culture that places "excessively rationalistic" criteria for inclusion in the moral community, what Post calls "exclusionary ethics" which erode "love, care and solicitude". The guiding premise is "unconditional equality" based on the "incomparable human worth that everyone has as a human being".

The book begins with a series of narratives of people with dementia, focusing on the positive experience possible in dementia. Post relates the "autobiographical" story of Jan ("only lightly edited"), who, while suffering from dementia, finds meaning in snow flakes: "It had snowed and I had truly forgotten what a beautiful sight a soft, gentle snowfall could be. . . . As I bent down to gather a mass of those radiantly white flakes on my shovel, it seemed as though I could do nothing but marvel at their beauty. God had granted me the ability to see a snowfall through the same innocent eyes of the child I once was. . . . My husband says I am more content now than ever before!...".

Post addresses some of the ethical issues around caring, including the ethical issues around the self-sacrifice of carers and of behaviour control. The chapter entitled, "Fairhill guidelines on ethics and care of people with Alzheimer Disease" provides a consensus statement resulting from a community dialogue on the ethics of dementia care which took place between 1993-4, involving a wide variety of professionals involved in dementia care. A set of ideal standards of care are outlined for the following areas: truth-telling, disclosure of diagnosis, driving privileges, behaviour control, promoting autonomy and competence, evaluating quality of life, and death and dying.

There is a chapter on pre-symptomatic psychological and genetic testing. Post is concerned about the cultural forces driving such testing, rule by "genocrats" and moral problems in aborting fetuses found to be at risk of developing Alzheimer Disease.

In the following chapter, Post shows himself to be sympathetic to a sanctity, rather than a quality, of life doctrine. He opposes assisted suicide: "assisted suicide in the context of terminal illness ... must be placed in a communitarian context in which responsibilities for the common good . . . have moral importance. People with severe incurable illnesses have responsibilities to maintain the general cultural prohibition against suicide as a routine response to life's inevitable challenges." Rather, Post advocates "affirmative dementia care", and putting more money into dementia care. $\mathrm{He}$ asserts the "incompatibility hypothesis": legalisation of assisted suicide and euthanasia is incompatible with the development of adequate comfort care for the demented and dying. Since assisted suicide and euthanasia "save money", there would be pressure on the demented to die in "hard economic times". "Why invest in dementia care research, training, and facilities when assisted suicide or mercy killing are already available and much cheaper?" (This claim is liable to a reductio: why, we might ask, in hard economic times, would treatment for any condition be developed when there is a cheap and readily available alternative, that is, no treatment?) While Post does not present evidence for his conjectures, he asks us to remember the Jewish aphorism: "Start worrying. Letter to follow."

There is a strong Christian religious perspective throughout the book. Post claims that people have the right to request so-called futile interventions for religious reasons, citing approvingly the artificial ventilation of Helga Wanglie, an 86-year-old woman in a permanent vegetative state. Despite the desire of Mrs Wanglie's physicians to stop artificial ventilation, a judge reaffirmed Mr Wanglie's right to request this treatment. $\mathrm{Mr}$ Wanglie's reasons were that physicians should not play God, she would not be better off dead, that to withdraw life support would be moral decay and a miracle might occur. Post claims that such treatment is not futile: it worked because it "kept Mrs Wanglie breathing, warm to the touch, and excreting waste products".

Even in very advanced dementia, there is much that can be done, according to Post. This is a part of Post's "discourse ethics": "One act of discourse is the extension of the hand, another is the tone of voice that reassures the person. This is the sort of basic act that makes resurrection of a sort possible. ..".

This book may provide hope for people with dementia and their carers. As a reviewer, I found that my own position as a rationalist prevented me from connecting with this book. No doubt others will be more enthusiastic.

Post does make some true claims. For example, I agree that it can be justifiable to provide life-prolonging 
treatment to people in a "permanent vegetative state". As Post implies, such lives are not clearly worse than being dead. However, the justifiability for me of such treatment turns on the extent that there is some chance of recovery. The basis is thus not religious faith, but medical scepticism, scepticism that such states really are "permanent". Such treatments are not clearly futile, as doctors sometimes claim. But I cannot accept Post's claim that survival of the body and the ability to excrete waste products is an existence worth prolonging. And perhaps the biggest moral challenge of Alzheimer Disease, Post does not consider. Even if we accept that there should be better care for demented people (as, presumably, everyone would agree, just as we would all agree that there should be no poverty and the world should be a better place), what priority should such care have in a world of limited resources? What are we prepared to deny other people to provide the Wanglies of this world with their hopes for a miracle? How much is a life with Alzheimer Disease worth? For me, appeal to "incomparable human worth" does not answer these important questions.

JULIAN SAVULESCU Clinical Ethicist, Oxford Radcliffe Hospitals, Oxford

\section{The Moral Roots of Prenatal Diagnosis. Ethical Aspects of the Early Introduction and Presentation of Prenatal Diagnosis in Sweden}

\author{
Christian Munthe, Gothenburg, \\ Centre for Research Ethics, 1996, \\ 88 pages, US\$15.00.
}

One of the most discussed medical techniques during the last two decades has been prenatal diagnosis. The technique itself is not controversial, rather its consequences. When there is a positive result, selective abortion is the controversial aspect of prenatal diagnosis. Above all, because of its possible consequences, complicated ethical problems arise. This technique is now in general use in clinical practice, but how did those who introduced prenatal diagnosis look upon the ethical problems during the introduction of the technique? Did they show any interest in them, or were these problems ignored? Which motives were the most important ones at the introduction? It is these questions which are the subject of this book. The author has examined the debate on prenatal diagnosis in Sweden during the period 1969-77. Why this period? Because it was during these years that the presentation and introduction of prenatal diagnosis took place in Sweden. It was also the period that preceded the intense debate that has since characterised prenatal diagnosis.

To get answers to his questions the author has used two sources of information. The primary one has been printed publications and the secondary source has been interviews with four leading medical specialists on prenatal diagnosis from the period in question and four critics from the debate after 1977. Along with many other things that have become clinical practice prenatal diagnosis does not seem to have been the result of deliberate research and development programmes. It is rather an incidental spin-off of basic medical research which eventually became clinical practice.

During the period 1969-77 the author found 64 articles mentioning prenatal diagnosis. He divided these into six categories: scientific, professional, patient-organisation, popular, daily and official. Eight items were written by ethicists and published in popular publications with a very small chance of reaching specialists, politicians or a larger audience. More than half of the articles were written by medical specialists.

The author found three perspectives which form the basis for the introduction of prenatal diagnosis in Sweden. The first he calls "the official view", the typical perspective embraced by the medical specialists. This is the view that prenatal diagnosis is a tool for genetic counselling: "the activity of determining the possibility of a pair of prospective parents to have a child with a certain medical condition, informing them about the result and also about possible lines of action on the basis of this result". There is no place for coercion, pressure or manipulation within the official view. Instead, this perspective is characterised by respect for the patient, and its purpose is to strengthen the patient's autonomy However, within this perspective therem were some controversies. Some medical specialists, for examples? argued that patients should agree to an abortion, if the test result turned? out positive, before being offered pre음 natal diagnosis. And some thoughto that anxiety should be included in the indications for prenatal diagnosis.

However, there are problems with this perspective not discussed in the book. One problem is that the patien $\overrightarrow{0}$ will not always understand the consequences of the information. A second $\vec{\omega}$ problem is that there is not much time before a decision has to be made about a possible abortion. The cruciaf question is how autonomous and free can the woman be in a situation of this kind?

The second perspective is called "the preventive aim". The purpose of this perspective is to prevent children? with genetic disorders from being born. This perspective is, from a philosophical point of view, very com는 plicated because it deals with ques $\stackrel{\infty}{\rightarrow}$ tions regarding the moral status of people who may or may not existgine the future. The interesting discussion on this problem covers the difficultyinterchangeability of possible futures persons and the moral status of poss $\overline{0}$ sible people. The preventive aim is in conflict with the official view's stress on respect for the patient as an autonomous person. Moreover this perspective ties prenatal diagnosis to the large and complex issue of the morality of abortion and especially? selective abortion.

The third perspective presented iso called "the economic motive". This perspective was put forward by? medical specialists who hoped that prenatal diagnosis would reduce the costs to society of caring for childreno with genetic disorders. The author distinguishes different interpretations of the economic motive, for example, one. honours the preventive aim, on eco $N$ nomic grounds, but does not observê the demand for respect of the auton? omy of the individual; whereas anothew excludes measures taken to restrict the autonomy of the individual.

An important conclusion of the author is that "ethical aspects were not? a very frequent subject in the special:ists' presentations". When a new tech nique, that may be controversial, iइ introduced in the medical context, the medical specialists very seldom discus $\$$ the ethical consequences of the tech nique, but rather discuss the technical and economic issues. But when a new 